\title{
The effect of dietary lipid saturation and antioxidant type on the performance of finishing lambs
}

\author{
K.E. van der Walt ${ }^{3}$, O.B. Einkamerer ${ }^{1 \#}$, H.J. van der Merwe ${ }^{1}$, A. Hugo $^{2}$, \\ S.C. Slippers ${ }^{3}$ \& M.D. Fair ${ }^{1}$ \\ ${ }^{1}$ Department of Animal, Wildlife and Grassland Sciences; ${ }^{2}$ Department of Microbial, Biochemical and Food \\ Biotechnology; ${ }^{1,2}$ Faculty of Natural and Agricultural Sciences, University of the Free State, P.O. Box 339, Bloemfontein \\ 9300, South Africa; ${ }^{3}$ Meadow Feeds, P.O. Box 6224, Weltevreden Park 1715, South Africa
}

(Received 4 January 2014; Accepted 5 June 2014; First published online 22 August 2014)

Copyright resides with the authors in terms of the Creative Commons Attribution 2.5 South African Licence.

See: http://creativecommons.org/licenses/by/2.5/za

Condition of use: The user may copy, distribute, transmit and adapt the work, but must recognise the authors and the South African Journal of Animal Science.

\begin{abstract}
The effect on production performance of a synthetic or natural antioxidant and lipid saturation in the finishing diets of lambs was investigated. The four dietary treatments consisted of the same basal diet $(187 \mathrm{~g}$ $\mathrm{CP}, 355 \mathrm{~g} \mathrm{NDF}$, and $71 \mathrm{~g}$ EE per $\mathrm{kg} \mathrm{DM})$, differing only in regard to the supplemental lipid source (30 $\mathrm{g} / \mathrm{kg}$ of either saturated beef tallow or unsaturated soybean oil) and type of antioxidant (125 g/ton of either a synthetic or natural antioxidant) included, in a $2 \times 2$ factorial design experiment. Eighty-four S.A. Mutton Merino lambs $(27.64 \pm 1.72 \mathrm{~kg})$ were randomly allocated to the four dietary treatments $(\mathrm{n}=21$ lambs per treatment) and subdivided into 7 replicates per treatment ( $n=3$ lambs per replicate). After a dietary adaptation period of 8 days, all lambs received the respective experimental diets for the remaining period (41 days). The average daily DM feed intake, weight gain and feed efficiency was calculated accordingly. No significant differences in DMI, ADG and the efficiency with which ingested feed were utilized (FCR), were recorded for the treatments. However, the addition of unsaturated soybean oil to the diet significantly increased the efficiency with which the ME of the diet was utilized. In contrast with the natural antioxidant, the inclusion of unsaturated soybean oil in the diet containing a synthetic antioxidant, resulted in a significant lower MEI by the lambs - indicating that a lipid $x$ antioxidant interaction occurred. Results of the present study seem to indicate that dietary lipid saturation in the finishing diets of lambs had no influence on their growth performance. However, a more efficient utilisation of ME in the finishing diet containing unsaturated soybean oil, compared to the saturated beef tallow, did occur.
\end{abstract}

Keywords: Fatty acid, flavonoid, metabolizable energy, oil, production, sheep, soybean, tallow

\#Corresponding author: Einkamererob@ufs.ac.za

\section{Introduction}

Lipids are important energy components in the diet of ruminants (Bauman et al., 2003) and contain on average up to 2.25 times more energy, compared to carbohydrates (McDonald et al., 2002). Feeding lipids differing in origin and the degree of saturation to ruminants may then result in a variety of responses in the levels of production (Felton \& Kerley, 2004), either by negatively affecting voluntary feed intake and fibre digestibility, or by not yielding consistent performance results (Manso et al., 2005). To be more specific, various researchers are of the opinion that added fat does not only increase the energy content of finishing diets, but may also increase the daily gain and feed efficiency of animals (Zinn, 1989). Numerous lipid sources have been shown either to improve feed efficiency or to have no effect (Brandt \& Anderson, 1990). Generally it is recommended that total lipid inclusion should not exceed $6 \%$ to $7 \%$ of the dietary dry matter (DM) content, otherwise a decrease in feed intake can occur, negating the advantages of increased energy density of the diet (Beauchemin et al., 2007).

Since unsaturated fatty acids (UFA) are vulnerable to oxidative degeneration (Smith et al., 2007), it may be favourable to supplement animal diets with additional antioxidant sources (natural or synthetic) to prevent feed flavour deterioration - which could then influence voluntary feed intake. Synthetic antioxidants can inhibit lipid oxidation in feed, but may exhibit adverse properties like carcinogenicity, resulting in strict regulations regarding their use in foods (Haak et al., 2006). These findings, together with increased 
resistance to the use of synthetic additives, have increased the interest in the properties of naturally occurring antioxidants (Simitzis \& Deligeorgis, 2010).

Flavonoids are thus some of these naturally occurring antioxidants. They are secondary plant metabolites derived from phenylalanine and acetyl co-enzyme A (Winkel-Shirley, 2001), that act as antioxidants (Ross \& Kasum, 2007). Furthermore, certain authors have reported that the addition of flavonoids and phenolic compounds (i.e. plant derived tannins) (Vasta et al., 2010) to ruminant feeds, may alter the microbial populations and consequently could affect the ruminal $\mathrm{pH}$ (increasing lactate-consuming micro-organisms) (Balcells et al., 2012) and DM intake (Jami et al., 2012). Consequently, flavonoids may not only act as natural antioxidants, but could also be considered as ruminal modifiers.

No information could currently be found in the literature regarding the effect of dietary lipid saturation, combined with either a natural or synthetic antioxidants, on the performance of lambs. Therefore, the aim of this study was to investigate the effect of a natural occurring bioflavonoid antioxidant and fatty acid saturation in a standard feedlot diet on the production performance of finishing lambs.

\section{Materials and Methods}

All procedures conducted during this study were approved by the Interfaculty Animal Ethics Committee for Animal Experimentation at the University of the Free State (Animal Experiment No. 04/2010).

Eighty-four S.A. Mutton Merino lambs $(27.64 \pm 1.72 \mathrm{~kg})$ were randomly allocated to four dietary treatments $(n=21$ lambs/treatment). Each treatment group was further subdivided into seven replicates consisting of three lambs per replicate. The three lambs in each replicate were housed in pens $\left(2.808 \mathrm{~m}^{2}\right)$ on slatted floors in a well-ventilated building. All animals were subjected to a standard health and vaccination program four weeks prior to the onset of the production study, as practiced in the commercial feedlot sector of South Africa. The lambs were also dosed with a broad spectrum parasite remedy and injected with a trace mineral optimizer.

A basal diet [187 $\mathrm{g}$ crude protein (CP), $355 \mathrm{~g}$ neutral detergent fibre (NDF) and $71 \mathrm{~g}$ ether extract (EE) per $\mathrm{kg}$ DM] was formulated, using the NRC (1985) requirements for finishing lambs as a guideline. Each basal diet were supplemented, according to a $2 \times 2$ factorial design, with one of two lipid sources (30 g/kg of either saturated beef tallow or unsaturated soybean oil), as well as type of antioxidant (125 g/ton of either a synthetic or natural antioxidant) - culminating into four dietary treatments. The four dietary treatments thus only differed with regard to lipid source and antioxidant type included. The synthetic antioxidant contained a combination of butylated hydroxyanisole (BHA), butylated hydroxytoluene (BHT), ethoxyquin, and trisodium citrate. The natural antioxidant being a poliphenolic plant extract containing bioflavonoids (cathecin and gallo-catchecin) and pro-anthocyanidins (which generate the anthocyanidins delfinidin, robinetidin and fisetidin).

At the onset of the production study all lambs were subjected to an eight-day adaptation period. Following dietary adaptation, each group was fed the respective treatment diets on an ad lib. basis for the remainder of the experimental period (41 days), until all the lambs attained an average live weight of approximately $48 \mathrm{~kg}$ prior to slaughter. The feed intake and body weights were recorded weekly and the average daily feed intake (DMI), weight gain (ADG) and feed conversion ratio (FCR), were calculated accordingly. All lambs had free access to clean, cool drinking water.

The data were subjected to PROC ANOVA and analysed according to a $2 \times 2$ factorial arrangement of treatments (lipid source $x$ antioxidant type) and tested for significant differences using the General Linear Model (GLM) procedures of the SAS program (SAS, 1999). Tukey's honest significant difference (HSD) test was used to identify significant differences $(P<0.05)$ between treatments (SAS, 1999).

\section{Results and Discussions}

The mean feed intake and production performance of lambs fed finishing diets containing different dietary antioxidant and lipid sources are presented in Table 1. From the results (Table 1 ) it would seem that lipid saturation and antioxidant type had no-significant $(P>0.05)$ influence on the dry matter intake (DMI) of the lambs. This was expected due to the similar dietary nutrient composition, especially NDF content (Booyens et al., 2013). It was evident that a lipid $x$ antioxidant interaction $(P<0.05)$ occurred for the metabolizable energy intake (MEI) of lambs. In contrast with the natural antioxidant, the inclusion of unsaturated soybean oil in the diet containing a synthetic antioxidant resulted in a significantly lower $(P$ $<0.001)$ MEl. This lower energy intake of the lambs could probably be explained by the negative effect of an unsaturated lipid source on fibre digestion and the ME content of the experimental diets, as recorded by Booyens et al. (2013). The non-significant $(P>0.05)$ effect of the unsaturated lipid on the MEl of lambs when a natural antioxidant was included in the diet is difficult to explain. No significant $(P>0.05)$ effect of antioxidant type on MEI was detected. 
From the results in Table 1 it is also evident that the saturation level of lipid source and type of antioxidant included had no effect $(P>0.05)$ on the final live weight, ADG and FCR of the lambs. These results did not support the lower MEI of the lambs fed the diet containing the synthetic antioxidant and unsaturated soyabean oil. It could be speculated that the heat increment and the methane $\left(\mathrm{CH}_{4}\right)$ production of this diet was lower and subsequently resulted in the same net energy (NE) intake. Micro-organisms in the rumen of ruminants generally generate heat through the fermentation of nutrients and McDonald et al. (2002) reported the heat increment of diets to vary considerably - according to the nature of the diet, the type of animal consuming it, and the processes by which the nutrients are utilized. This heat of fermentation is then especially generated from the fibre content in the diet. As the inclusion of an unsaturated lipid source has a negative effect on fibre digestibility due to its antimicrobial (Palmquist \& Jenkins, 1980) and coating (Firkins \& Eastridge, 1994; Harris, 2003) effect, it could result in less energy being lost as heat in the rumen - resulting in more energy being available for productive purposes by the animal. The reduced production of ruminal $\mathrm{CH}_{4}$ within the unsaturated treatment, as reported by Booyens et al. (2013), could also contribute to the nonsignificant differences recorded. Therefore, both the heat increment of fermentation, as well as $\mathrm{CH}_{4}$ production was probably reduced by the unsaturated lipid source, resulting in the non-significant differences.

Table 1 The mean feed intake and production performance of lambs fed diets containing different dietary antioxidant and lipid sources

\begin{tabular}{|c|c|c|c|c|c|c|c|}
\hline \multirow{2}{*}{ Parameter } & \multirow{2}{*}{$\begin{array}{l}\text { Antioxidant } \\
\text { (125 g/ton) }\end{array}$} & \multicolumn{2}{|c|}{ Lipid source (30 g/kg) } & \multirow[b]{2}{*}{ Mean } & \multicolumn{3}{|c|}{ Significance ( $P$-value) } \\
\hline & & Saturated & Unsaturated & & $\begin{array}{c}\text { Lipid } \\
\text { source }\end{array}$ & Antioxidant & Interaction \\
\hline \multicolumn{8}{|l|}{ Intake: } \\
\hline Dry matter intake & Synthetic & 1641 & 1605 & 1623 & 0.5626 & 0.1408 & 05911 \\
\hline \multirow[t]{2}{*}{ (g/lamb/day) } & Natural & 1575 & 1573 & 1574 & & & \\
\hline & Mean & 1608 & 1589 & & & & \\
\hline $\mathrm{MEI}^{\#}$ & Synthetic & $16.68^{\mathrm{a}}$ & $14.96^{\mathrm{b}}$ & & 0.0014 & 0.6308 & 0.0438 \\
\hline (MJ/lamb/day) & Natural & 15.89 & 15.45 & & & & \\
\hline \multicolumn{8}{|c|}{ Production performance: } \\
\hline Initial weight* & Synthetic & 27.68 & 27.69 & 27.68 & 0.9605 & 0.8235 & 0.9703 \\
\hline \multirow[t]{2}{*}{ (day 0) } & Natural & 27.58 & 27.61 & 27.60 & & & \\
\hline & Mean & 27.63 & 27.65 & & & & \\
\hline End weight* & Chemical & 45.53 & 45.51 & 45.52 & 0.5648 & 0.2133 & 0.5454 \\
\hline \multirow[t]{2}{*}{ (day 49) } & Natural & 44.31 & 45.09 & 44.70 & & & \\
\hline & Mean & 44.92 & 45.30 & & & & \\
\hline $\mathrm{ADG}^{\#}$ & Synthetic & 364 & 364 & 364 & 0.4946 & 0.1642 & 0.4666 \\
\hline \multirow[t]{2}{*}{ (g/sheep/day) } & Natural & 341 & 357 & 349 & & & \\
\hline & Mean & 353 & 360 & & & & \\
\hline $\mathrm{FCR}^{\#}(\mathrm{~kg} \mathrm{DM}$ & Synthetic & 4.51 & 4.42 & 4.47 & 0.1307 & 0.5159 & 0.5267 \\
\hline feed intake/kg & Natural & 4.64 & 4.42 & 4.53 & & & \\
\hline live weight gain) & Mean & 4.58 & 4.42 & & & & \\
\hline $\mathrm{MJ} \mathrm{ME}^{\#} / \mathrm{kg}$ live & Synthetic & 45.86 & 41.21 & 43.54 & 0.0003 & 0.1118 & 0.5140 \\
\hline \multirow[t]{2}{*}{ weight gain } & Natural & 46.82 & 43.44 & 45.13 & & & \\
\hline & Mean & $46.34^{b}$ & $42.33^{\mathrm{a}}$ & & & & \\
\hline
\end{tabular}

In contrast with DMI, ADG and FCR, the inclusion of an unsaturated lipid source in the form of soybean oil resulted in a significantly $(P<0.001)$ better utilisation of ME in the experimental diet $($ Table 1$)$. 
This could be attributed to the lower $(P<0.05)$ ME content of the unsaturated soybean oil diet (Booyens et al., 2013), and non-significant $(P>0.05)$ differences in DMI and ADG between lipid sources. From Table 1 is it clear that the source of antioxidant did not influence $(P>0.05)$ the efficiency of ME utilisation by the experimental lambs.

The findings of the present study supports those of Zinn (1989) and Bock et al. (1991) who reported that feeding soybean soap stock, or a blend of soybean oil and tallow, did not affect the DMI, ADG, or feed efficiency of steers, compared to tallow or yellow grease. Accordingly, Beauchemin et al. (2007) found no effect $(P>0.05)$ regarding the DMI and ADG of Angus heifers fed diets containing $3.4 \%$ of either saturated tallow or more unsaturated sunflower oil.

Studies conducted to assess the effects of lipids on the performance of ruminants have however not yielded consistent results (Doreau \& Chilliard, 1997). Manso et al. (2005) was of the opinion that this could be due to a variety of factors, such as the level and/or source of dietary fat and the nature of the basal diet which can determine the effects of added lipids on the ruminal microbes.

\section{Conclusions}

Results of the present study indicate that dietary lipid saturation in finishing diets of lambs has no influence on DMI, ADG or FCR. However, a more efficient utilisation of ME in the finishing diet containing unsaturated soybean oil, compared to saturated beef tallow, did occur. It further appears from the results that the inclusion of a synthetic or natural antioxidant in the finishing diets of lambs had no effect on the same parameters mentioned. The significant responses in terms of production efficiency are important, considering the paucity of research concerning the effect of lipid saturation and antioxidant source on these parameters.

\section{Acknowledgements}

The authors wish to acknowledge Meadow Feeds and Biorem Biological Products for their technical and financial support during this study.

\section{References}

Balcells, J., Aris, A., Serrano, A., Seradj, A.R., Crespo, J. \& Devant, M., 2012. Effects of an extract of plant flavonoids $\left(\right.$ Bioflavex ${ }^{\circledR}$ ) on rumen fermentation and performance in heifers fed high-concentrate diets. J. Anim. Sci. Published online as doi: 10.2527/jas.2011-4955.

Bauman, D.E., Perfield II, J.W., De Veth, M.J. \& Lock, A.L., 2003. New perspective on lipid digestion and metabolism in ruminants. Proc. Cornell Nutrition Conference. pp. 175-189.

Beauchemin, K.A., McGinn, S.M. \& Petit, H.V., 2007. Methane abatement strategies for cattle: Lipid supplementation of diets. Can. J. Anim. Sci. 87, 431-440.

Bock, B.J., Harmon, D.L., Brandt, R.T., Schneider Jr, J.E. \& Schneider, J.E., 1991. Fat source and calcium level effects on finishing steer performance, digestion and metabolism. J. Anim. Sci. 69:2211-2224.

Booyens, K.E., Einkamerer, O.B., Van der Merwe, H.J., Hugo, A., Slippers, S.C. \& Fair, M.D., 2013. The effect of dietary lipid saturation and antioxidant source on the nutrient digestibility of lamb finishing diets. Proc. $45^{\text {th }}$ Congress of the South African Society for Animal Science. S. Afr. J. Anim. Sci., 43 (Issue 5, Suppl. 1), S22-S26.

Brandt, R.T. \& Anderson, S.J., 1990. Supplemental fat source affects feedlot performance and carcass traits of finishing yearling steers and estimated diet net energy value. J. Anim. Sci. 68, 2208-2216.

Doreau, M. \& Chilliard, Y., 1997. Digestion and metabolism of dietary fat in farm animals. Br. J. Nutr. 78, 15-35.

Felton, E.E.D. \& Kerley, M.S., 2004. Performance and carcass quality of steers fed different sources of dietary fat. J. Anim. Sci. 82, 1794-1805.

Firkins, J.L. \& Eastridge, M.L., 1994. Assessment of the effects of iodine value on fatty acid digestibility, feed intake, and milk production. J. Dairy Sci. 77, 2357-2366.

Haak, L., Raes, K., Smet, K., Claeys, E., Paelinck, P. \& De Smet, S., 2006. Effect of dietary antioxidant and fatty acid supply on the oxidative stability of fresh and cooked pork. Meat Sci. 74, 476-486.

Harris, B., 2003. Using fat in lactating cow ration. University of Florida. IFAS Extention. DS19. pp. 1-8.

Jami, E., Shabtay, A., Nikbachat, M., Yosef, E., Miron, J. \& Mizrahi, I., 2012. Effects of adding a concentrated pomegranate-residue extract to the ration of lactating cows on in vivo digestibility and profile of rumen bacterial population. J. Dairy Sci. 95, 1-10.

Manso, T., Castro, T., Mantecón, A.R. \& Jimeno, V., 2005. Effects of palm oil and calcium soaps of palm oil fatty acids in fattening diets on digestibility, performance and chemical body composition of lambs. Anim. Feed Sci. Technol. 127, 175-186.

McDonald, P., Edwards, R.A., Greenhalgh, J.F.D. \& Morgan, C.A., 2002. Animal Nutrition. $6^{\text {th }}$ Edition. Pearson Prentice Hall. 
NRC, 1985. Nutrient Requirements of Sheep. $6^{\text {th }}$ edition. National Academy of Sciences. Washington D.C. Palmquist, D.L. \& Jenkins, T.C., 1980. Fat in lactation rations: review. J. Dairy Sci. 63, 1-14.

Ross, J.A. \& Kasum, C.M., 2007. Dietary flavonoids: bioavailability, metabolic effects and safety. Ann. Rev. Nutr. 22, 19-34.

SAS, 1999. Statistical Analysis System user's guide ( $6^{\text {th }}$ edition). SAS Institute Inc., Raleigh, North Carolina, USA.

Smith, S.A., King, R.E. \& Min, D.B., 2007. Oxidative and thermal stabilities of genetically modified high oleic sunflower oil. Food Chem. 102, 1208-1213.

Simitzis, P.E. \& Deligeorgis, S.G., 2010. Lipid oxidation of meat and use of essential oils as antioxidants in meat products. http://www.scitopics.com/Lipid_Oxidation_of_Meat_and_Use_of_Essential_ Oils_as_Antioxidants_in_Meat_Products.html [March 2011].

Vasta, V., Yanez-Ruiz, D.R., Mele, M., Serra, A., Luciano, G., Lanza, M., Biondi, L. \& Priolo, A., 2010. Bacterial and protozoal communities and fatty acid profile in the rumen of sheep fed a diet containing added tannins. Appl. Environ. Microbiol. 74 (8), 2549-2555.

Winkel-Shirley, B., 2001. Flavonoid biosynthesis. A colourful model for genetics, biochemistry, cell biology, and biotechnology. Plant Physiol. 126, 485-493.

Zinn, R.A., 1989. Influence of level and source of dietary fat on its comparative feeding value in finishing diets for steers: Feedlot cattle growth and performance. J. Anim. Sci. 67, 1029-1037. 